\title{
POLIPOSIS INTESTINAL GENERALIZADA
}

\author{
Por los Dres. ALFREDO GANTZ, RAIMUNDO ARIZTIA y ALBERTO GUZMAN \\ Hospital Clínico dz Niños Roberto del Rio,
}

Enferma de 8 años de edad que tuvimos ocasión de presentar a una de las reuniones clínjcas del hospital, con el diagnóstico de invaginación intestinal izquierda, baja, sigmoídea y poliposis rectal; cuya historia me permitiré repetir para el mejor relato del caso.

Antecedentes bereditarios: Padres vivos $y$ sanos. No hay antecedentes de tuberculosis. Cinco bijos vivos y sanos. Kahn ( - ) en el padre.

Antecedentes personales: Coqueluche. Sarampión. Ascaridiósls hace 2 años.

Enfermedad actual; Niña con antecedentes de constipación, que desde febrero de 1948 acude a Policlinica de Medicina por vómitos y dolores abdominales. Desde guagua presentaba prolapso rectal, por lo cual fué operada en el Hospital Arriarán, según contaba el padre, donde permaneció hospitalizada un mes. Pasó un año sin molestias. Después se reprodujo el prolapso, aunque con menor intenstdad. Sangraba con facllddad. Hace 4 meses afarece el prolapso en forma muy intensa $y$ desde hace 4 dias presenta vónitos intensos, acompañados de cólicos intestinales. Vomitaba hasta el agua. Consulta a Policlínica de Medicina, donde le indican tratamiento a base de luminal.

Ilevaba 3 días sin deposición. Siguteron los vómitos y los dolores, y como no presentaba deposteiones, la madre le practica un enema jabonoso. Ellminó escasa cantidad de excrementos muy duros. Fit día de ingreso al Serviclo, 30 de abril de 1950, se colocó un nuevo enema, obrando en gran cantldad y al final Ellmina sangre fresca y coágulos. Ingresón al Servicio de Primeros Auxillos, presentando un cóaguio en el anllo rectal. Los vómltos eran bliosas y a veces de mal olor; este último dato no es muy exacto.

Examen físico: Wnferma con palidez intensa. Piel deshidratada. Temperatura rectal: 37.5. Presión: $9 / 6$.

Cabeza: Dentadura: nada especial. Faringe: (-). Lengus: seca, saburral; labjos pall- dos, clanóticos. Aliento nauseoso. OJos: ConJuntivas pálidas, con inyección discreta.

Tórax: Pulmones: nada especial. Corazón: taquicardia, tonos sin alteración.

Abdomen: flácido, deprimido, en batea con solevantamiento visible en el hemiabdomen lzquierdo, especialmente en la región de la fosa lliaca y paraumbilícal. A la palpaclón: blando, depresible e indoloro, con una masa desplazable a nivel de la fosa ilíaca izquierda, que se continua hacia arriba cast hasta el htpocondrio tzquierdo. No es dolorosa a la palpación y da la impresión de intestino.

Figado y bazo: nada especial.

Ano: presenta un coáguio que sale a través de él con facilidad, otro fijo que se reduce.

Tacto rectal: se palpa una masa, a $8 \mathrm{~cm}$ del ano, que da la impresión de pólipo; otro más pequeño, un poco más alto. Se aprecia una masa más arriba. Al retirar el dedo sale cubierto de sangre fresca.

Enema salino: de $600 \mathrm{cc}$, al comlenzo entra con diflcultad, luego sin resistencla. La palpación abdominal cambia radicalmente, pues desaparece la masa que se palpaba anteriormente. Al eliminar el líquido aparece con pequeñas estrías de sangre. Abdomen completamente depresible.

se practicó transfusión de sangre de $100 \mathrm{cc}$. Se deja alimentación a base de líquidos.

Continúa tranquila, sin vómitos; pero no presenta depasiciones. Dos días después se pidió tránsito intestlnal y enema haritado, que fueron normales. Un hemograma ditó anemia discreta y desviación a la izquierda con leucocitosis. Radíoscopía de tórax: foco calchficado base pulmón izqulerdo.

continúa blen y a los 9 dias de su ingreso se da de alta sin molestias y con Indlcaciones de control.

Desgraciedamente, la enferma, como muchas otras, no se presentó al control requet1do $y$ al volver al hospital se obtienen los siguientes datos: permanecló blen, sin molestias hasta el 7 de octubre del 50 , en que bruscamente presenta crisis dolorosa abdominal y prolapso rectal, por lo cual se hospitaliza el dia 10 de octubre.

Ingresa una enfermita muy enflaquecida, en pésimo estado general, sensorio despejado. 
Quejumbrosa. Temperatura; 38. PuIso: 134 . Presión: 9/4. Llama la atención en su cara la pigmentación de los labios y mucosa bucal. Boca: lenglia saburral. Faringe roja con amigdalas hipertróficas. Tórax: nada especial. EI abdomen globuloso, tenso, muy doloroso, lo cual dificulta la paipación. Hígado a un través de dedo por debajo del reborde costal. Bazo: nada especial. Extremidades: reflejos más intensos al lado izquierdo.

Se piden los siguientes exámenes:

Uremia: 0.30 . Orina: nada especial. Sedimentacion: $28 \mathrm{~mm}$. Reacciones tificas: negativas. Baciloscopias del desgarro: negativas. Fibras elásticas: negativas. Kahn: negativo. Examen directo de deposiciones, en busca de bacilos Koch: negativo. Hemograma: rojos, $3.00,000$; mono. 3; linfo., 4; segm., 35; bacil., 58; Hb., $53 \%$; leucocitos, 15,1100 .

Se dejó con extracto suprarrenal, suero glucosado y cafeína.

El día 13 de octubre se le practica una radioscopía pulmonar, que sólo da un foco calcificado de la base izquierda. Reacción de Mantoux al 1 por 100: positiva.

El dia 14, en vista que persiste el cuadro doloroso abdomina], el meteorismo, y con el resultado de los exámenes de radioscopia $y$ Mantoux, se hace el diagnóstico de peritonitis tuberculosa, iniciándose tratamlento con estreptomicina, medio gramo cada 12 horas. Las deposiciones eran de 1 a 2 dlarias, no habiendo constancia especial si iban o no acompañadas de sangre.

A su vez se pide un tránsito intestinal, que da un esófago y estrimargo normales. A la 11/2 hora. el estómago está casi vacio y el bario ocupa en forma irregular el intestino delgado. A las $41 / 2$ horas el bario contrasta irregularmente las últimas asas del delgado, el ileon aparece dilatado, empieza a llenarse el ciego. A las 24 horas, pequeños restos de bario en el clego; el resto ocupa el colon descendente la $\mathbf{S}$ iliaca y el recto.

La enferma siguió evolucionando con temperatura de 38 y $381 / 2$. ICon palidez muy marcada. El abdomen stempre meteorizado y doloroso, a aumentando lentamente la medición del perimetro abdominal. 터 día 20 aparecen anotadas en la historia las primeras deposiciones con sangre. Al día siguiente el dolor abdominal se agudiza y aparecen vomitos biliosos; tuvo deposiciones.

La palpación hecha por el médico de sa1a. acusa: En la fesa ilíaca izquierda una masa que sobrepasa hacia el flanco derecho y muy dolorosa. Las vómitos son casi permanentes,.. on el tratamienta se..agrega peniclina y luminal. El día 22 , en vista que continuaba, este cuadiro doloroso, con vomitos Fermanentes; con alza de temperatura, hasta $40^{\circ}$, es examinada por el cirujano y el médico de guardia, quienas comprueban una enferma en anemia aguda, por lo cual se practica una transfusión de urgencia. Con respecto al abdomen, no se palpa masa sospechosa de invaginación. Agregan al tratamiento suero glucosado y atropina. Fl dia 23 amanece con temperatura de $40^{\circ}$, vómitos permanentes, que desde el día anterior tienen carácter sanguinolento. Uno de nosotros es llamado a examinar esta enferma, por haberia atendido en su hospitalización anterior, y se encuentra con una enfermita en pésimo estado general, con sintomas francos de anemia aguda. El examen abdominal revelaba to sieuiente: $A$ la inspección, abdomen en batea, de paredes flácidas, sobre las cuales se dibujan movimientos peristálticos, sobresallendo una masa tumoral en la región del epigastrio con prolongación hacia el hipocondrio izquierdo, flanco y fosa ilíaca del mismo lado, que a la palpación es caracteristica de un intestino invaginado " que de trecho en trecho presenta tumores más pequeños, duros, que parecen estar englobados en dicha masa. Hecho el diagnóstico clínico de invaginación intestinal, por el cual ya había sido hospitalizada una vez, se trata de mejorar algo el estado general para que pueda resistir una intervención quirúrgica. Se coloca una transfusión de urgencia de 250 cc a presión y con otra de gota a gota se lleva al pabellón, aun en condiciones muy desfavorables.

Bajo anestesia de cloro-éter se practlca una laparotomía transrectal derecha. Ablerto el peritoneo se comprueba una gran cantidad de líquido y una masa de intestino invaginado que ocupa toda la región ya anteriormente descrita, o sea, desde la fosa ilía ea izquierda, ascendiendo hacia el epigastrio, llegando hasta el ángulo duodeno-yeyunal, sitio en el cual hay, además de la invaginaclón, una torsión que impide deshacer el budín. El intestino delgado ha desaparecido completamente, estando englobado en la invaginación. Durante estas maniobras la enferma fallece, por lo cual se suspende la operación para poder practicar una autopsia prolija. Esta ültima dió como resultado una poliposis intestinal generalizada, cuyas características serán narradas por el Dr. Guzmán en el informe siguiente:

M. C. O. - 8 años. - 23-X-1950. - Santa Filomena. - 50/21124.

Encéfalo: pesó $1,200 \mathrm{~g}$, bien conformado, de consistencia firme.

Caviead toráxica: Timo: atroflado.

Corazón: pesó $68 \mathrm{~g}$, tamaño normal, mide $8.6 \mathrm{~cm}$ de alto por $7.5 \mathrm{~cm}$ de ancho, en diástole; miocardio turbio, congestivo.

Puimones: congestivos, enfisematosos, sin focos densos.

Ganglios peribronquiales: de tamaño normal, presentan ligera congestión.

Cavidad abdominal: Bazo: peś́ $40 \mathrm{~g}$, tamaño y consistencia normales. Hígado: peso 500 
$g$, de tamaño grande, congestivo; permeabilidad biliar normal.

Riñones: congestivos, turbios, la cápsula se desprende con facilidad; el riñón izquierdo tiene doble pelyls, mide $9 \mathrm{~cm}$ por $4.5 \mathrm{~cm}$, pesó $58 \mathrm{gr}$; el derecho mide $7 \mathrm{~cm}$ por $5 \mathrm{~cm} \mathrm{y} \mathrm{pesó}$ $30 \mathrm{~g}$.

Páncreas: tamaño y consistencla normales (se dejó con el duodeno).

Suprarrenales: muy, bien conservadas, de tamaño normal, aspecto anémico.

Ganglios mesantéricos: congestivos, hemorrágicos del tamaño de un poroto corriente.

Mucosa gástrica: congestionada, vasos bien a la vista, plozada presenta en la superficie contenido mucódeo abundante de coloracions verdosa.

Intestino: asas del intestino delgado muy đilatadas; de coloración violácea oscura; esta coloración comienza a pocos centimetros por eneima de Ia válpula íleocecal. El colon trans. verso está ligeramente dilatado $z$ de coloración violácea, se constatan dos adherencias firmes del intestino delgado entre sí, las cuales forman un verdadero anillo mesentérico. Se encuentra una morcilla gruesa de invaginación en la parte alta del tntestino delgado a nivel del comienzo del yeyuno; Ia asa de yeyuno invaginada presenta la pared de coloración rojiza oscura friable. En el intestino desenvaginado presenta en su superficie un exudado amarillento con grumos acumulados por ia invaginación. Superficie externa del intestino invaginado gris rojiza edematosa con manchas hemorrágleas $y$ con un exudado fibrinoso adherido. La mucasa a nivel del intestino invaginado estâ tumefacta, rojiza, en parte ulcerada; a este nivel llamán la atención masas poltpoideas que tienen un pedículo alargado delgado y una especie de cabeza en la parte superior; estos pólipos se encuentran reyartidos en todo el intestino, desde el duodeno hasta el recto, y miden desde $1 \mathrm{~cm}$ hasta $4 \mathrm{~cm}$ de alto; se encontraron hasta 40 pólipos. Se encuentra una porción de intestino delgado de más o menos 1 metro $65 \mathrm{~cm}$, desde la válvula ileocecal hacia arriba sin pólipos. Llam ma la atención, al apretar el recto, se prolapsa la mucosa por un ano amplio relajado. Se encontró abundante contenido intestinal hemorragico.

Conclusión: Invaginación intestinal alta (comíenzo del yeyuno).

Polifosis intestinal generalizada.

\section{Dr. Alberto Gurmản F.}

Refiriéndonos a la poliposis y a los pólipos intestinales en el niño, diremos lo siguiente:

Los pólipos intestinales son un cuadro relativamente frecuente, presentando su mayor incidencia entre los 2 y $\operatorname{los} 8$ años, con un máximo a los 5 . En cuanto a sexo hay un pequeño predominio de los hombres 54 : 38.

Pueden localizarse en cualquiera parte del intestino, pero con mayor frecuencia en el recto.

Cuando su número es exagerado se constituye una entìdad nosológica denominada poliposis, ocupando entre éstas un cuadro bien diferenciado la poliposis familiar del colon. Su principal caracteristica la constituye una gran cantidad de pólipos, generalmente conglomerados, que ocultan completamente el aspecto normal de la mucosa, constituyendo verdaderas placas espesas, dispuestas en hileras ordenadas y que Broders lama polipoidosis. Tiene un carácter familiar hereditario, aparentemente cominante.

La teoría que afirmaba su aparición en la pubertad fué descartada por Me. Kenny, quien logró presentar un caso en un niño menor de 2 años. Dixson describe otro enfermo de 18 meses.

De este cuadro se han descrito alrededor de 400 casos familiares, primando si en todos ellos la aparición tardía de los sintomas y el alto porcentaje de degeneración maligna, entre un 26 a $36 \%$.

Ia sintomatologia se caracteriza por dolores abdominales, deposiciones sanguinolentas y diarrea frecuentes.

E1 tratamiento para este tipo de afección es quirúrgico, yendo desde la cauterio-sección hasta la colectomía en uno o varios tiempos, con anastomosis íleorectal.

Respecto a poliposis generalizada del intestino, Ladd y Gross describen un sola caso.

En cuanto a la etiología de la poliposis en general, Feyrter la considera como adquirida por inflamaciones clónicas. La encuentra en un $24 \%$ de las autopsias y casi sin excepción sobre los 75 años de edad. Casi nunca faltan en las colitis crónicas ulcerosas. Por otra parte, no es raro que la poliposis del recto dé el cuadro de colitis.

Sintomatología: Melenas, muchas veces ocultas, por lo cual debe investigarse la presencia de sangre en las deposicio- 
nes. Esto es lo más frecuente. Este sintoma puede conducir a la anemia.

Dolores abdominales que van desde el tipo leve hasta el cólico, el cual indicaría un comienzo de invaginación, lo cual se debe a la inclusión de estas hiperplasias adenomatosas en las ondas peristálticas del intestino; serían arrastradas hacia la sub-mucosa, facilitando la invaginación con esta interferencia.

Para el diagnóstico es de importancia el hallazgo de pólipos rectales y sigmoídeos, o aun la eliminación espontánea de trozos de pólipos. La presencia de múltiples pólipos en estas regiones, sería indicación para ir a un examen radiológico prolijo. Para esto se practicará un tránsito intestinal y un enema baritado, lo cual permite observar defectos de llenamiento así como las retenciones de bario.

El diagnóstico diferencial hay que hacerlo con todas aquellas afecciones capaces de producir melena, como ser: La constipación. Las fisuras anales. El divertículo de Meckel, cuya hemorragia comienza repentina y silenciosamente. La invaginación intestinal. El escorbuto $\mathrm{y}$ discrasias sanguíneas. Ulceras del tubo digestivo, etc.

Complicaciones: Por orden de frecuencia tenemos: la hemorragia, la invaginación y la degeneración maligna.

Tratamiento: Es quirúrgico y dependerá de la localización de el o los pólipos. Si es único o al menos escaso, se puede practicar la extirpación a través del recto o sigmoidoscopio. De preferencia se hace la amputación con electrocoagulación.

Otro tipo de operación es la extirpación a través de una laparotomía seguida de ileotomía o colotomía. Esto para aquellos pólipos que están fuera del alcance del instrumental antes mencionado.

Un tercer tipo son las colostomias temporales. Así se hace sigmoidostomía, colostomia del transverso o cecostomía, se- gún la ubicación de los pólipos. Por la boca de la ostomía se introduce un rectoscopio, en un segundo tiempo, y se practica la resección de los pólipos.

Finalmente, la colectomía. Es el tratamiento de elección en las poliposis avanzadas del colon.

Finalmente, diremos que para numerosos autores la radiografía es ineficaz en estos casos.

Debido a la extensión de las lesiones en las piezas de autopsia del caso presentado, como ustedes podrán apreciar, creemos que la intervención quirúrgica no habría dado resultados en ningún caso.

\section{Summary.}

A case of generalized intestinal polyposis in an 8 year old girl is presented. The authors review the literature on this subject.

\section{Bibliografía.}

Bockuls, H. L. - Gastroenterología, Salvat. Barcelona. 1948.

BRFNNEMANI'S PRACTICE OF PEDIATRICs. W. F. Prior ICompany, Inc. Hawerstown, Maryland. 1948.

'CHRISTOPHER, F. - A Textbook of surgery. W. B. Saunders Company. Philadelphta \& London. 1944.

COHRBANDT-KARGER-BEIRGMANN. - Chlrurgtsche Krankhelten in Kindesalter. $\mathbf{s}$. Karger. Berlin, 1928.

HOLT, L. E. y HOWLAND, J. - Tratado de Pediatria, Unatón Tipográfica Editorial Hispano Amerlcana. México.

JIMEANEZ DIAZ, IC. - Lecclones de Patologia Médica. Ed. Científico-Médica. Madrid, Barcelona. 1940. Tercera Edición.

LADD, W. E. and GROSS, R. E. - Abdomínal Surgery of Infancy and Childhood. W. B. Saunders Company. Philadelphta \& London. 1941 .

MITCHALL-NELSON. - Texthook of Pediatrics. W. B. Saunders Company. Philadelphia \& London. 1950 .

PFAUINDLER, M. v. y SCHLOSSMANN, A. Tratado enciclopédico de enfermedades de la infancia. Francisco Seix. Barcelona, 1034. 